\title{
Flesh Machine - Vision Machine - War Machine
}

\author{
Catherine Bernard \\ State University of New York \\ College at Old Westbury \\ Bernardc@oldwestbury.edu
}

\begin{abstract}
Flesh Machine, Vision Machine, War Machine discusses the political and ideological impacts of fast developing technologies on our apprehension of the world and looks at the work of artists who examine the consequences of our entanglement to the flesh machine, the impact of surveillance technologies and that of distance wars.
\end{abstract}

Flesh. Vision. War. Technology. Distance. Apparatus. Drone. Data. Surveillance. Machine.

\section{INTRODUCTION}

Current artistic practices that look at issues of human and machine interface, reveal the boundaries limiting physical bodies and expose some of the consequences of the new technological paradigm while they underline the growing obsolescence of physical experiences in our daily lives. This essay proposes to discuss the work of a few artists whose work looks at human and non-human agency. They apply a critique of the human/machine interface and investigate the position of the subject within a set of relations to the world of which physical distance and invisibility are the keys.

I would like to start this discussion by looking at the machine as an apparatus, a social and political construction of which technology is a structural and central part. It might also be useful to imagine the idea of machine as one that designates an assemblage, a heterogenic construct of which the human, although at times presented as obsolete, is nonetheless an integrated part that interfaces with the other dimensions of the machine-apparatus. The flesh, vision and war machines might be interpreted as constructs that are for a good part at the service of the global hegemony as it is analysed by Noam Chomsky (Chomsky 2003). That these can become the tools of political and social manipulations and abuses of power is an obvious fact corroborated by such disclosures made by Edward Snowden and other whistle blowers.

A common and specific character of the flesh, vision and war machines --or apparatuses-- in addition to their ability to create distance from the physical experience, is their invisibility. The genomic and biotech industries are operating in the secrecy of high tech labs, the vision machine is made up of a staggering number of signals that operate at a no less staggering speed, carefully hidden in structures invisible to the common eyes and buried deep in the oceans, the deserts, or hovering in space, undetectable by the human eye. Electronic warfare dissimulates its movements and its targets, while the location of the terrain is abstracted from the human context, and is engaged in the semi voyeuristic manipulation of a distant other through its distance and invisibility capacity.

\section{FLESH MACHINE}

Twenty years ago, the Critical Art Ensemble published The Flesh Machine (Critical Art Ensemble 1998). The book looked at the relation between technology and manipulations of the body and raised questions regarding the development of a new eugenic consciousness. The predictions of the activist group have been exceeded and the traditional boundary between engineering and medical science erased. This field of experimentation is very much tied to corporate biotech attempts at normalising the body to maintain a

maximum social functionality. The flesh machine has for mission to monitor, control and alter the 
physical body. I will focus here on the work of two artist collectives that were key in establishing a critical approach to the development of the Flesh machine and its consequences in our socio cultural current landscape.

\subsection{Floating point unit - fakeshop}

These two artists collectives: Floating point Unit or FPU and fakeshop were active in New York City from the early to late 1990s and examined the interface body/technology with live broadcast performances on the Net. During that time, they pioneered Net art and raised questions linked to the dematerialisation of the physical body with their performances while also building digital strategies of resistance to the control society and the expansion of surveillance systems. These ideas were central to the use of FPU CU-SeeMe environments in which performance participants were watched on monitors by outside viewers intruding into their physical space.

Antonin Artaud's vision of the natural body as a dysfunctional and poorly constructed machine

A scene from the 1994 movie Coma, in which the bodies of involuntary organ donors in a state of perpetual coma are shown suspended from wires, inspired the 1999 fakeshop performance Multiple_Dwellings at Ars Electronica. A scaffolding constructed with metallic structures included suspended platforms used during the performance for the observation, scanning and accumulation of bio-data by cameras and computers from the unresponsive bodies. At the same time, remote network participants around the world symbolically sold and bought the participants' organs, thus redesigning their bodies. The performance presented physical reality as co-constructed between different subjectivities and categories, while it also addressed the idea of the bio-economy of body parts. One of bio-economy most disturbing aspect is the trafficking of human organs, where the kidney hunter profession is not part of a sci-fi movie, but a ruthless form of exploitation of habitants in poor countries for the benefit of western patients.

From 1994 to 2000, FPU and fakeshop collaborative performances focused on the politics of the flesh and instigated questions about posthuman bodies and bio-economy. Their performances looked at the body as part of a social design, a process facilitated by a dematerialisation and digitalisation of the marked by psychosis was an important source for the performances of FPU and fakeshop. Artaud envisioned the theater as a place where the body could be dissected, split and cut open as a means for healing and reconstitute the self. The 1996 FPU performance Body Without Organs played with the transmutations of the body and the flesh, and the dematerialisation of the physical experience. The phrase originally coined by Artaud, was later used by Deleuze and Guattari in their account of the genesis of the schizophrenic subject. FPU created a cyberorganised being, the organs of which were to be extruded, re-routed and re-signified by an electronic anatomy. During the Body Without Organs performance, the web body waspixilated and reconstructed through live feeds that encouraged the distortions and manipulations of remote participants bodies as an assembled collection of Cu-SeeMe windows, where bodies took shape as digital embodiments, encoded and reconfigured as systems of electronic synapses.

physical space that promote the model of a quantifiable body and its dissociation from experienced reality. In these performances, both collectives looked at the body as a site of physical and economic reconstruction in a post industrial era preoccupied by the development of genetic engineering and developing technologies such as cloning, Germline therapy, Tissue Engineering or designer's babies. The latest products of the biotech industry take the form of embedded sensors or epidermal tattoos collecting precise emissions from the brain, heart and muscles. Such augmented bodies enhance biometric tracking. And while these new technologies result in successful medical applications, it is safe to say that they encompass an Orwellian vision of the flesh machine as one engineering forms of control of physical identity and consciousness. A perfected body, one that can transcend age, disease and decay, is a commodity prized fort its economic value. The unpredictability of the body and physical experience is difficult to manage and needs to be organised within a cycle of production and consumption. In Next Bodies, feminist theorist Faith Wilding, who collaborated with Critical Art Ensemble to Flesh Machine, writes a scathing analysis of the transformations of the female body, colonised as a laboratory for a lucrative medical and pharmaceutical industry.

\section{Organic bodies and bodily processes -}


particularly those of women and fetuses are being invaded at the molecular level and reengineered to meet the cyborgian and eugenic requirements of a rationalized global work force and consumer market. (Wilding 2001)

\section{VISION MACHINE}

\subsection{Data insomnia}

In his 1968 Video Corridor, Bruce Nauman installed surveillance cameras at either end of a corridor. With this dispositif the viewer was at once audience and subject defining thus the several levels at which surveillance operates: that of looking, voyeurism and spying.

In parallel to the flesh machine, the monitoring of the physical environment by the vision machine has become a trope of our lives and its sleepless presence accompanies our quotidian gestures. Computer keyboards, video cameras and other devices relay signals to large monitoring entities that probe into every recesses of the human activity. The vision machine extends its surveillance capacities to reach outer space as suggested by a recent acknowledgment by the Pentagon of decades of secret intelligence and information gathering related to extra terrestrial life (BBC 2017). In 2014, the NSA completed the Utah Data Center, designed to store data on the order of exabytes. The spyware data center is located in a desert environment in the northern part of Utah and is the largest of its kind. It uses, among other systems, PRISM, a code name for a program under which the NSA harvests live Internet communications as well as voice chats and texts. The enormous amount of harvested data passes through this reflecting and refracting prismatic power, generating a continuous flow (Carroll 2013).

The monitoring of citizens in large urban centers around the world is now an established practice. Since $9 / 11$ it has become a trope in the life of entire groups of population. The Muslim

The activities engaged by Frontex in Eastern Europe, around the Mediterranean and off the West African coastal waters are not monitored, and serious issues of human rights breaches that result in the deaths of many economic and political refugees, are left unchecked. Frontex is a symbol of the ideology of fortress Europe that accompanies the rise of nationalist governments there and elsewhere. population in New York City has been since that date under constant surveillance, every aspect of its members daily lives being monitored. In 2011, The Associated Press released documents compiled over a decade by a special police unit, whose task was to record every activity of members of that community such as shopping, exercising, restaurant going, etc. (Hawley 2012).

\subsection{Monitoring the borders}

Borders in many parts of the Northern hemisphere are monitored by distance technologies such as high capacity surveillance cameras, satellites that relay information on the ground about movements of populations, boats etc. Extraterrestrial satellites in particular, epitomise the desire of dominance through verticality and a higher observation vantage over the populations on the ground.

Mission and Task (2012-2013) by Julian Röder is a series of photographs that document the different surveillance apparatuses used by Frontex around the Mediterranean region, Eastern Europe and other entry points in Europe to control immigrant and refugees population. Frontex, the European Border and Coastal Guard Agency headquartered in Warsaw, controls the Schengen area and coordinates the border and coast guards of the member states.

Röder photographs show distance monitoring from planes, drones and guards looking out from very long distances onto migrant and refugee groups. The data collected with this high tech surveillance equipment is analysed and enables border patrols and agents to make decisions based on a risk management analytic system that traces, forecasts and interprets the information relayed by cameras, drones and satellites. Equipped with the results, Frontex uses a tactic called "diversion" to send thousands of people back to West Africa or the Near East as if they were human cargo. In other cases, migrants are detained in facilities that do not meet basic human rights standards. (Human Rights Watch 2011).

\subsection{The Drone stare}

Between November 1997 and February 1998, the Bureau of Inverse Technology launched and flew a remote control plane, (the term drone didn't exist at the time) through Silicon Valley, nose mounted with a miniature video camera and transmitter, recording images of large tech campuses, arguably the first pieces of drone art. 
The Silicon Valley corporate campuses were all no camera zones, where visitors had to leave their camera at the entrance, with the charge that information could be stolen. The Plane Project acted as a gesture allowing to gaze back at the information technology and military centers and breaching their secrecy with a counter surveillance action. The BIT project brought attention to the emergence of the new surveillance systems that were starting to expand, experimented with network technologies and examined the nature and dissemination of information (Simon 2015).

Such process is subject to and impacted by the value system of those operating the machines and the resulting technological or tragic human errors are seldom reported as they would upset the rationalisation narrative justifying the use of drones. It is the function of the drone stare to dehumanise the bodies of those who serve as the targets of remote monitoring. In recent years, the military use of drone technology has increased in assisting with border control operations and the monitoring of urban populations in so called high risk neighborhoods of large cities and in the US are part of the militarisation of urban areas and of the ongoing subjugation of others, whether immigrants or minorities.

The inspiration for Hito Steyerl's 2013 video How Not to be Seen: a Fucking Didactic Educational MOV.13 was a story about devices used by Afghan rebels to avoid being detected by drones (Steyerl \& Poitras 2015). Because drones detect movement and body heat, the rebels cover themselves with reflective plastic sheets, pour water on themselves to bring down their body temperatures while remaining immobile until the drones leave the area. The video reads as a parody of didactic short films, inspired by instructional and DIY films. It gives five lessons of invisibility, describing acts of disappearance to go off the grid, and composing a guide of counter surveillance tactics similar to those used by the civilian populations on the ground targeted by military drones. With computer generated images paired with actual footage, Steyerl questions the reality and veracity of images reduced to cyphers by the drone stare, while also bringing up questions about actual disappearance of people in war. The film responds also to the condition of hyper visibility that has emerged since 2011 , in which those being scrutinized become quantifiable data and are not seen. The accumulation, dissemination and archiving of
Drones have become ubiquitous machines of the surveillance economy, gathering massive amounts of data analyzed according to risks probabilities models, which are used to manage populations, sites and network convergences that exceed what is classified as acceptable risks thresholds. The vision machine interprets the data harvested by drones and eliminates differences with techniques that homogenise the information and reduce it to simpler categories applied to the definition of acceptable risk.

images is in many cases used to establish watch lists or targets. How Not to be Seen addresses the paradox of hyper visibility and invisibility in the life of citizens and in military operations. It is another way to return the drone stare.

\section{WAR MACHINE}

Deleuze and Guattari concept of a war machine as an anarchic presence on the far horizon of the state defying its range of order and totalitarianism, with its nomadic warriors' alterity to the disciplined state subject, is turned upside down in $21^{\text {st }}$ warfare. The war machine that looms on the horizon of every battlefield of the Middle East, Afghanistan, Yemen or Somalia is the tangible form of what is heralded as a new world order that, if it indeed transcends the borders of the state, has nonetheless evolved into a machine at the orders of the corporatocracy and its ally, the arm industry. The notion of deterritorialization, dear to the Deleuzian concept, as one warding off the grafting of the local onto a final social or political order and the transfer and stockpiling of its resources to a central bureaucracy, is irreversibly transformed by the organizational logic of the meta structures of the global geo-political order. Ushering this change, science fiction has started to play out on battlefields with the expanded use of robots by western governments, while others are catching up rapidly. John Basett, a security consultant with GCHQ, the Government Communications Headquarters in the UK states:

At some point around 2025 or there about the US Army will actually have more combat robots than it will have human soldiers. (Lockett 2017) 
In early April 2018, experts on military artificial intelligence from more than 80 countries converged onto the UN offices in Geneva to discuss autonomous weapon systems. It was agreed that we are now on the brink of a third revolution warfare, heralded by robots, fully autonomous weapon systems that can decide who to target and kill without human input. Algorithms direct the paths of a new generation of autonomous drones that behave as a collective organism, a swarm, adapting to each other and responding to a shared brain in real time (Perrigo 2018). The real time of the war machine data is uniform and seamless and replaces the time of duration, the lived time of territorial and physical inscriptions. The technological evolution equips robots and other military equipment with artificial intelligence, laser vision and the possibility of recall. These autonomous military weapons are increasingly described as having agency, and even objects with consciousness, or hybrid organisms who might one day supersede human agency. Such descriptions feed the discourse on the power of the machine and its potential to overcome humanity, a sci-fi narrative of diversion, useful in masquerading the real mechanisms at work, those of the battle for hegemonistic global power.

Indeed the war machine is the crux of enormous financial powers held by private arm industries that cater to various governments, escalate the arm race and the creation of conflicts that in the end benefit these same industries. The war machine is at the service of global corporations that profit from it and have a large share of power in world governments. In his 2017 Shadow World, film director Johan Grimonprez investigates the developments of the war machine and the mechanisms of the arms trade, its links to neocapitalism and governments deals while also highlighting the growth of distance wars.

\subsection{Eye machine}

Withthe Eye/Machine Trilogy (2001-2003) Harun Farocki chose to focus on the images of the 19901991 first Gulf War that can perhaps be considered as the liminal test for the war/vision machine experiment.

During that war, the limits between images taken from distance, those taken by the bomber planes, those of the reporters on the ground and computer simulated images became blurred. The images distributed by the Pentagon and those diffused in the medias infiltrated the public domain and the politics of the image became the center of a debate about their reliability and the obsolescence of human observation. What was at stake was the fabrication of weaponized images that during the first Gulf war became part of electronic warfare. Part of this process was the use of operational images both generated and read by machines that do not need to be made by humans or read by humans anymore. These images have

a primary technical and functional purpose, are produced for specific operations and destined to be erased, for example images taken by military surveillance to verify the efficiency of a bombing mission (Blümlinger 2004). By researching such images and using them, Farocki reload them with a social and political value, while he rescues them from invisibility and deconstructs their significance within the economy of the war machine. By using montage as a way to organise the images, Farocki creates semantic associations that reveal their value in mounting the spectacle of war.

Farocki's Eye/Machine questions our status as spectators and the logic of war that such images, relayed by the dominant media, imply. The artist reveals the ambiguity of their meaning and show how several layers converge to contribute to the mediatic construction of the war. The way images circulate in the social space helps to design and define it. Conversely, the way Farocki organises the images can be understood as a political gesture demonstrating their semantic potential. This work embodies issues of image agency, visibility and contingency.

\subsection{Drones again}

Distance warfare articulates the violence of imperialism similar in that way to how distance surveillance articulates the violence of nationalism over borders and migrant populations. Armed drones have been used by the CIA over Afghanistan since 2001 as part of a global war system.

\author{
Understood as a metaphor of power, drone \\ technology represents the migration \\ of power from something vested in the \\ territorial claims of sovereign nations \\ to the space-extending ambitions of trans- \\ sovereign empires for which \\ only the projection of power has political \\ currency. (Kroker 2015)
}

Their flexibility and speed are portrayed as strategic responses to the decentralization of 
terrorism as well as to the fluid movements of immigrant and refugee populations. The staggering expansion of drone missions from the US and its allies since the war on terror (Wall, Monahan 2011) and the ethical issues they imply are compounded by the secrecy surrounding their use. The invisibility of drones is paralleled with that of the military personnel operating them. Images of military UAVs are confined to official photos given to the press and images of strikes and their consequences are even more difficult to find. Drones are manned by soldiers dissociated from the physical experience of combat, who operate from control centers thousands of miles away from their target and who drive home after their shift. Recent studies have shown that distance killing creates similar of higher levels of combat stress and PTSD for them than for military personnel physically deployed on the ground (Press 2018).

The impact of distance killing on the civilian populations and the particular psychological effect on drone

operators are discussed in 5000 Feet is the Best, a 2011 film by Omer Fast whose title refers to the optimum altitude at which a US air force drone can identify targets on the ground. Several layers of cinematographic syntax convey the horror of anonymous and invisible drone strikes, their consequences and the impact at the source through testimonies recorded and filmed by Fast.

Blue Sky Days (2013-14) by Tomas van Houtryve has for origin a drone strike in northeast Pakistan in October 2012 that killed a 67-year-old woman picking okra outside her house. In 2013 in Washington, DC, the woman's 13-year-old grandson, Zubair Rehman, spoke to a group of five lawmakers:

Now I prefer cloudy days when the drones don't fly. When the sky brightens and becomes blue, the drones return and so does the fear. Children don't play so often now, and have stopped going to school. (McVeigh 2013)

With a camera attached to a small drone, van Houtryve travelled across the US and photographed groups of people assembled for different social gatherings such as a wedding or a base ball game that, viewed from above, create visual patterns similar to those targeted for military strikes in Pakistan, Afghanistan, Yemen or Somalia. His images mirror the geometric topology followed by the drone stare and allow the viewer to see the world from a drone's point of view while they also reveal the potential arbitrary nature of their vertical bird's-eye views and data analysis.

The project@NotABugSplat was realised by an artist collective from Pakistan. The title references the expression used by drone operators that compares the images of humans on the ground to bugs squashed by drone attacks. The work, a 90' x60' photograph printed on white tarpaulin is based on a portrait by Noor Behram taken in 2011, of a child who lost her parents and siblings in a drone strike. It was installed in the Khyber Pakhtunkhwa region of Pakistan, a heavily targeted area by US drones. The project is an attempt at rendering visible the human presence obscured by data harvesting and addresses directly drone operators by intervening in their visual field in the hope -perhaps naïve- of generating empathy.

\section{It (\#NotABugSplat) travels alongside a form of human right discourse that substitutes the abstraction of data with the density of narrative (Feldman 2016)}

In its local form, the project was short lived (Feldman 2016) as the habitants of the village repurposed the tarpaulin but its dissemination through digital media platforms reached a globalised audience. It should be noted however that this global reach could well be understood as being part of the construct of an enlightened humanitarism entangled with the imperialist gaze and spectatorship. After all the War on Terror is supported by the visual content circulated through various media. Perhaps then more importantly, the project brings forth the question of global visuality as form of imperialist authority, central to the war machine where targets are identified through metadata projecting human existence in forensic terms. With this project, \#NotABugSplat re-appropriated a territory occupied by the imaginary geographies of the war machine.

I will briefly conclude by stating the obvious: the flesh, vision and war machines and their accompanying technologies greatly impact our individual lives and our societies. Their growing presences and the physical distance created by their large scope applications are supported by industrial management and the creation of systems that insure the integration of individual 
bodies and social bodies, in order to maximise their operational capacities. These aspects serve as clear evidence of the need for a critique of the political, social and ideological mechanisms surrounding bio, surveillance and weapon technologies and for a discussion of the present state of existing/being in this new economy of relation. The need to assess the consequences of the new technological paradigm cannot be rooted in the fear of a science fiction takeover but in the careful analysis of its mechanisms. The entanglement of the individual body and of the social body with distance technologies creates forms of disembodied experiences that are

fundamentally transforming our lives. The understanding of our place in the world is mediated by huge networks of information and the collection of massive amounts of data and is determined by exchanges

that must transit through codes. This describes a process of formalisation that, as it becomes more performing, becomes also more institutionalised. When we can interact and interface without speaking of seeing one another and when our social structure becomes a sum of recombinant parts, then it becomes easy to perhaps envision an eventual disappearance of the subject and its agency.

\section{REFERENCES}

BBC. (2017) Pentagon ran secret multi-million dollar UFO programme. https://www.bbc.com/news/world-us-canada42379749 and CIA releases $13 \mathrm{~m}$ pages of declassified document online. http://www.bbc.com/news/world-us-canada38663522. Retrieved 12 March 2018.

Blümlinger, C. (2004) Harun Farocki: Critical Strategies. In Thomas Elsaesser (ed.), Harun Farocki: Working on the Sight-Lines. Amsterdam University Press, Amsterdam.

Carroll, R. (2013) Welcome to Utah, the NSA's desert home for eavesdropping on America. The Guardian.

https://www.theguardian.com/world/2013/jun/14/ nsa-utah-data-facility. Retrieved 7 February 2018.

Chomsky, N. (2003) Hegemony of Survival: America's Quest for Global Dominance. Metropolitan Books, New York.
Critical Art Ensemble (1998) Flesh Machine. Autonomedia, New York.

Feldman, K. (2018) \#NotABugSplat: Becoming Human on the Terrain of Visual Culture. In McClennen, S., Schultheis Moore A. (eds). The Routledge Companion to Literature and Human Rights. Routledge, London and New York. p.230.

Hawley, C. (2012) NYPD monitored Muslim students all over Northeast. Associated Press. https://www.ap.org/ap-in-the-news/2012/nypdmonitored-muslim-students-all-over-northeast. Retrieved 20 April 2018.

Human Rights Watch (2011) The EU's dirty hands.

https://www.hrw.org/sites/default/files/reports/gre ece0911webwcover_0.pdf. Retrieved 10 March 2018.

Kroker, A., Kroker, M., (2015) Surveillance never Sleeps: Dreaming with Drones, ctheory.net, $21 \mathrm{C} 007$.

http://ctheory.net/ctheory_wp/surveillance-neversleeps-2-dreaming-with-drones/. Retrieved 6 June 2018.

Lockett, J. (2017) US military will have more combat robots than humans soldiers by 2025 . New York Post, June 15, 2017.

McVeigh K., Drone strikes: tears in Congress as Pakistani family tells of mother's death. The Guardian, oct. 29, 2013 https://www.theguardian.com/world/2013/oct/29/ pakistan-family-drone-victim-testimony-congress. Retrieved 15 February 2018.

Perrigo, B. (2018) A Global Arms Race for Killer Robots is Transforming the Battlefield. Time magazine.

http://time.com/5230567/killer-robots/. Retrieved 15 April 2018.

$$
\begin{gathered}
\text { Flesh machine - War Machine - Vision Machine } \\
\text { Bernard }
\end{gathered}
$$

Press, E. (2018) The Wounds of the Drone Warrior. New York Times magazine, June 17, 2018, p.30. 
Simon, L. (2015) Interview with Natalie

Jeremijenko. Center for the Study of the Drone.

Audio. 00:20:43.

https://soundcloud.com/drone-center-at-

bard/natalie-jeremijenko-interview. Retrieved 20

April 2018.

Steyerl, H., Poitras, L. (2015) Techniques of the

Observer. Art Forum, 53 (9).

https://www.artforum.com/print/201505/techniqu

es-of-the-observer-hito-steyerl-and-laura-

poitras-in-conversation-51563. Retrieved 25 April

2018.

Van Houtryve, T. (2014) Blues Skies Days.

https://tomasvh.com/works/blue-sky-days/.

Retrieved 15 February 2018.

Wall T., Monahan T., (2011) Surveillance and violence from afar: The politics of drones and liminal security-scapes. Theoretical Criminology, 15 (3), pp. 239-254.

Wilding, F (2001) Next Bodies. In Amelia Jones (ed.), Feminism and Visual Culture: $A$ Reader. Routledge, New York. 